\title{
Addition of Hydroxyapatite to Toothpaste and Its Effect to Dentin Remineralization
}

\author{
Alexander Sadiasa, Jang Dong-Woo, Subrata Deb Nath, \\ Hyung Seok Seo*, Hyn Mo Yang and Byong Taek Lee ${ }^{\dagger}$ \\ Department of Biomedical Engineering and Materials, Soonchunhyang University, 366-1, \\ Ssangyoung-dong, Cheonan, Chungnam 330-090, Korea \\ *Department of Exercise Prescription, Konyang University, Dahak Ro Nae-dong Non San City, \\ Chung Nam Province, Korea
}

(Received December 20, 2012 : Received in revised form February 20, 2013 : Accepted February 26, 2013)

\begin{abstract}
In this study, hydroxyapatite (HAp) was incorporated into toothpaste and its effect on the remineralization and restoration of dental enamel was evaluated. Different sets of toothpaste were incorporated with HAp levels of $0 \%, 5 \%, 10 \%$, and $15 \%$. The filler particles of the resulting toothpaste samples were observed via SEM and XRD and compared with compositions of several commercially available toothpastes, showing that the HAp was successfully incorporated into the toothpaste samples. Different sets of human enamel were inflicted with lesions and then treated with the different fabricated toothpaste samples for five minutes three times a day for seven days. During the treatment, the teeth were subjected to demineralization and remineralization cycles to simulate the effect of natural saliva. The surface of the enamel samples were observed using SEM before and after one week of treatment, showing the formation of HAp layers on the surfaces of the enamel samples. The effect of the toothpaste on the lesions was observed using an inverted light microscope and the lesion depth was found to decrease as the concentration of HAp in the toothpaste used increased. HAp was successfully incorporated in the toothpaste and its presence was found to lessen lesion depths and improve tooth remineralization.
\end{abstract}

Key words toothpaste, hydroxyapatite, HAp, teeth, dental.

\section{Introduction}

Dental enamel is regarded as the hardest substance in the human body due to its high mineral content and it makes teeth possess good physical properties with a combination of high wear and fracture resistance. ${ }^{1,2)}$ But, dental lesions may form due to the loss of surface minerals due to bacterial infection. Inability to completely remove these lesions may result in the entrapment of active bacteria, which may continue to increase in number, resulting in abundant production of toxins. This situation is the start of the exposure of denatured collagen matrix and further development of tooth cavities. ${ }^{3,4)}$

Human teeth undergo many processes every day that contributes to its slow degradation and other problems concerning dental lesions. These activities or factors include ageing, constant grinding and exposure to acids, dental injuries and surface demineralization. These activities cause dental ailments such as hypersensitivity, discoloration of the teeth, production of dental lesions and other abnormalities that may lead to eventual loss of the affected teeth. Dental caries is one of the most prevalent oral diseases worldwide.,6)

Fluoride has been the usual answer to the problem of dental caries. A decline in dental caries among industrialized countries has been recorded following the widespread use of fluoride. ${ }^{7)}$ Recognition of the effect of fluoride against dental caries has spurred investigations concerning its actions on the inhibition and prevention of dental carries, with the goal of clinical applications. This has resulted in the incorporation of fluoride in many products used by individuals on a daily basis, such as water, salt and milk, among many examples. ${ }^{8)}$ Clinical observations suggest that provision of fluoride to vehicles is effective

\footnotetext{
Corresponding author

E-Mail : lbt@sch.ac.kr (B. T. Lee, Soonchunhyang Univ.)
}

(C) Materials Research Society of Korea, All rights reserved.

This is an Open-Access article distributed under the terms of the Creative Commons Attribution Non-Commercial License (http://creativecommons.org/licenses/by-nc/3.0) which permits unrestricted non-commercial use, distribution, and reproduction in any medium, provided the original work is properly cited. 
against caries development. The most popular vehicle is toothpaste, which serves as the principle means of the topical delivery of fluoride. ${ }^{9)}$ It was observed that the higher the fluoride content, the greater the anti-caries activity. ${ }^{10)}$ However, use of fluoride can be insufficient in eradicating dental caries. ${ }^{11-13)}$ Also, the excessive intake of fluoride can cause fluorosis, a visually detectable change in enamel opacity that can also affect dental functions, which has limited the consumption of fluoride to a minimal content. ${ }^{14,15)}$ Thus, there is a need to develop new approaches in treating dental caries and prevent its development. ${ }^{13,16)}$

Hydroxyapatite(HAp) has always been widely accepted medically due to its biocompatibility and is considered to be bioactive. It is more famously used as a component of bone substitutes. ${ }^{17)}$ In the field of dentistry, HAp is considered to be chemically similar to enamel. Investigations regarding these similarities show that the ultra-structures of dental enamel are composed of inorganic components distributed in the forms of rod and prisms of hexagonal hydroxyapatite crystals. ${ }^{2)}$ Application of HAp to damaged enamel has attracted great interest due to the similarity to enamel. ${ }^{5,18,19)}$ The use of HAp as a filler in dental restoration has several advantages, such as intrinsic radio-opaque response, enhanced polishing ability, improved wear performance and less expensive than the materials commonly used in dental health care, which have bolstered its appeal. ${ }^{20)}$

This study aimed to determine the effect of HAp on the restoration of teeth, especially dental lesions. To deliver and apply HAp for dental restoration, fabrication of toothpaste incorporated with HAp was conducted in this study. Different sets of toothpaste were prepared containing varying concentrations of HAp. This is done to analyze the effect of increasing content of HAp in the toothpaste, with the aim of formulating toothpaste comprised of a definite ratio of toothpaste ingredients and HAp to attain the optimal result. The toothpaste formulations were studied for their effect on tooth remineralization and treatment of dental lesions.

\section{Experimental Procedure}

\subsection{Synthesis of Hydroxyapatite}

Synthesis of HAp powders was done using a microwavehydrothermal system. The starting material for the production of $\mathrm{HAp}$ included calcium nitrate tetrahydrate $\left(\mathrm{Ca}\left(\mathrm{NO}_{3}\right)_{2} \cdot 4 \mathrm{H}_{2} \mathrm{O}, 98.5 \%\right.$; SAMCHUN Chemicals, Seoul, South Korea) and ammonium phosphate $\left(\left(\mathrm{NH}_{4}\right)_{2} \mathrm{HPO}_{4}\right.$, $98.5 \%$; SAMCHUN Chemicals, Seoul, South Korea). The materials were mixed with water separately and stirred until completely dissolved. The solutions were prepared with the reactants at a weight molar ratio of 1.17-1.77. The solutions were combined and stirred for $10 \mathrm{~min}$. The resulting single solution was transferred to a closed-vessel microwave device constructed of perfluoralkoxy(PFA) Teflon and exposed to $1200 \mathrm{~W}$ of output power generated by a dual magnetron device using $2.45 \mathrm{GHz}$ frequency microwave radiation. Three milliliters of deionized water was added to the resulting mixture, followed by a three-step procedure. The first step was a warming-up process generated at $250 \mathrm{~W}$ for $2 \mathrm{~min}$. The second step was a main reaction process generated at $250-650 \mathrm{~W}$ for $4 \mathrm{~min}$. The final step was a 20 -min cooling process. After completion of HAp synthesis, both the elimination of residuals in products and the crystallization of powders were achieved by microwave heating at $250 \mathrm{~W}$ for $3 \mathrm{~min}$. Samples containing 0\%, 5\%, $10 \%$ and $15 \%$ HAp were prepared and used in this experiment.

\subsection{Preparation of Toothpaste Slurries}

The synthesized HAp was incorporated in toothpaste slurries with varying concentrations. Toothpaste slurries containing $0 \%, 5 \%, 10 \%$ and $15 \%$ HAp were prepared and labeled TP-HP0, TP-HP5, TP-HP10 and TP-HP15, respectively. For the preparation of the slurries, distilled water was added to the mixture of the toothpaste and HAp in a 3:1 ratio according to EN ISO 11609(European Standards for preparing artificial saliva/toothpaste slurries). The mixture was stirred until it became homogenous and was then subjected to centrifugation at $3500 \mathrm{rpm}$ for 25 $\min$. The liquid was eliminated and the solid portion was retained to be used as toothpaste.

\subsection{Test Sample Characterization}

The toothpaste preparations were dried in aluminum foil and dried in a laminar flow hood. Surface morphologies of the toothpastes were observed using scanning electron microscopy(SEM) with a JSM-635 apparatus (JEOL, Tokyo, Japan). Samples were fixed in a sample holder and coated with platinum using a SPI-module Sputter coater at $7 \mathrm{~mA}$. Also, the surface morphology of commercially available toothpastes advertised to contain HAp were examined as a point of comparison. The toothpastes were once again dissolved in water and filtered to attain its filler particles. The attained substance were dried under a laminar hood and observed using SEM. EDS profiles of the samples were also determined using SEM to ensure the complete incorporation of HAp into the toothpaste.

\subsection{X-ray Diffraction(XRD) Profile Analysis}

The samples were analyzed to determine their XRD patterns. Each sample was then filtered with a filter paper and the filler materials of the toothpaste were pulverized prior to XRD analysis using a D/Max-250 apparatus (Rigaku, Tokyo, Japan). The machine was set to emit 
$\mathrm{CuK} \alpha$ radiation and generate $40 \mathrm{kV}$ and $200 \mathrm{~mA}$ with a varying diffraction angle of 20-40 degrees and an angle rate of 2 degrees $/ \mathrm{min}$. A sample of HAp was also made to undergo the process as a point of comparison.

\subsection{Particle Size Analysis}

Size of the particles of the synthesized HAp was attained using a particle size analyzer(Malvern Instruments, Malvern, UK) and analyzed using the Mastersizer S Ver. 2.19 program.

\subsection{Preparation of Human Enamel Test Samples}

Human enamel samples were obtained and were verified as being free of lesions, cavities and other abnormalities. The samples were immersed in ethanol to clean the surface and inhibit microbial growth. The teeth were then examined using the aforementioned SEM apparatus before and after polishing. SEM images were also obtained for the human enamels after the treatment period.

\subsection{Preparation of Artificial Lesions/cavities}

The prepared teeth samples were scoured with a diamond cutter to create artificial carious lesions as described previously(Metsaw 2004 R\&B Inc., Daejeon, South Korea). The resulting cavities were then examined using a model BX51 inverted light optical microscope(Olympus, Japan) and the area size of the cavities were measured before and after the treatment using the accompanying CellSens software.

\subsection{PH Cycling Model}

The human enamels to be tested were subjected to $\mathrm{pH}$ cycling for treatment with the respective toothpastes. The remineralizing solution was composed of $0.114 \% \mathrm{KCl}$, $0.0738 \% \mathrm{KH}_{2} \mathrm{PO}_{4}, 0.0738 \% \mathrm{NaCl}, 1.033 \% \mathrm{MgCl}_{2}, 0.213$ $\% \mathrm{CaCl}_{2} \cdot 2 \mathrm{H} 2 \mathrm{O}$, and $\mathrm{NaOH}$ was used to adjust the $\mathrm{pH}$ to 6.8. The demineralizing solution was composed of 0.1 $\mathrm{mM}$ sodium fluoride( $\mathrm{NaF}), 2.2 \mathrm{mM}$ calcium chloride dehydrate $\left(\mathrm{CaCl}_{2} .2 \mathrm{H}_{2} \mathrm{O}\right), 2.2 \mathrm{mM}$ potassium dihydrogen phosphate $\left(\mathrm{KH}_{2} \mathrm{PO}_{4}\right), 50 \mathrm{mM}$ acetic acid $\left(\mathrm{CH}_{3} \mathrm{COOH}\right)$, and the solution was maintained at $\mathrm{pH} 5.0$ using $10 \mathrm{mM}$ potassium hydroxide $(\mathrm{KOH})$. The 24 hour $\mathrm{pH}$ cycling system is depicted in Fig. 6. The human enamel samples were placed in the cycling system for 7 days. Each 24 hour schedule included three 5-minute treatments of the human samples using the fabricated toothpastes. After the second treatment, the human enamels were made to undergo demineralization. For the remaining time, the human enamels were placed in the remineralizing solution. Treatment of the human enamel included a 1-minute brushing of the test samples using the fabricated toothpastes. The brushings were applied using an electronic toothbrush in a
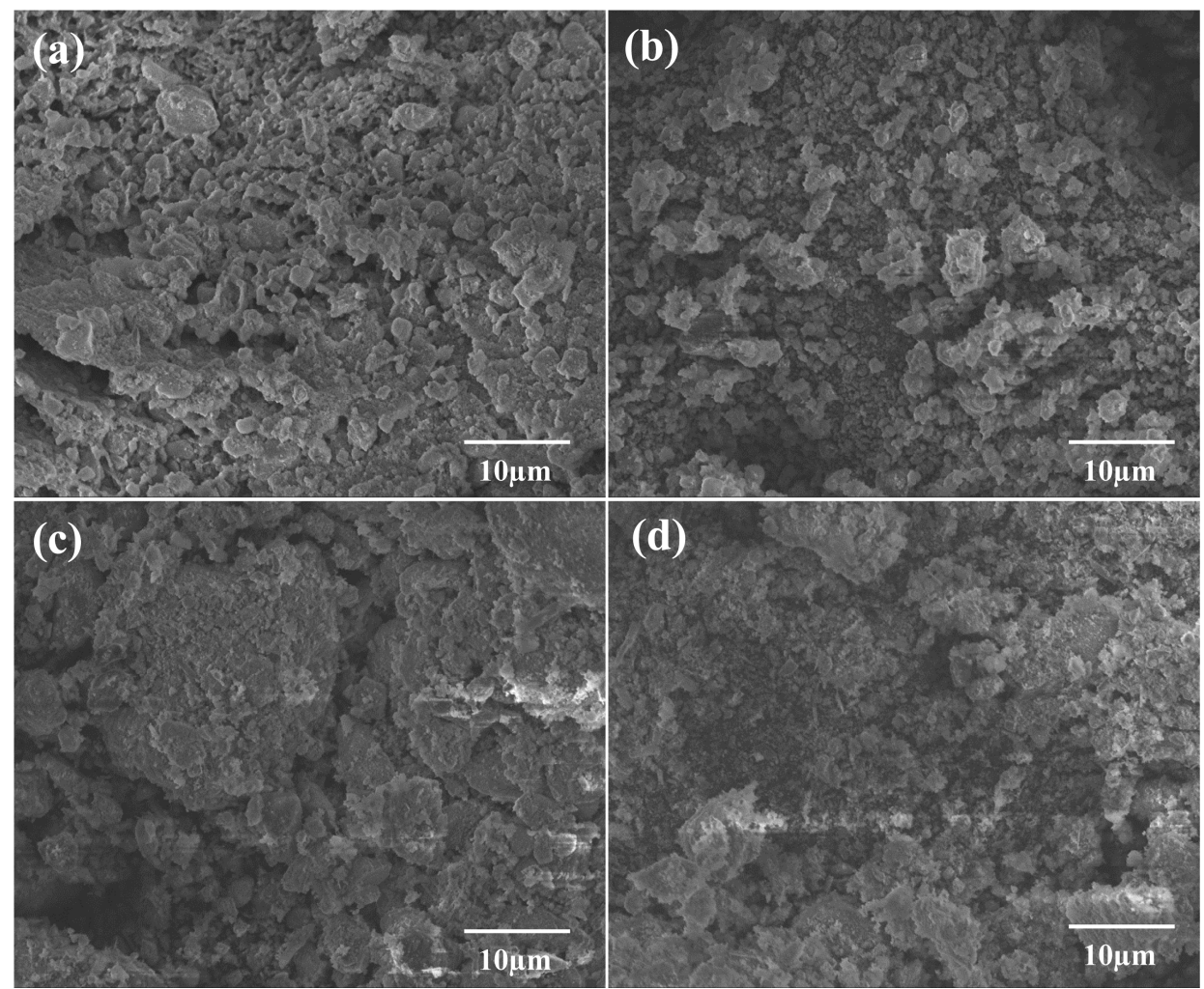

Fig. 1. SEM images of the toothpastes' surfaces (a) Commercial toothpaste (CT-A ), (b) Commercial toothpaste (CT-B), (c) Toothpaste without HAp and (d) Toothpaste with Hap. 
fixed position that was positioned to brush a sample placed in a clamp. All brushings were made at an equal speed set by the electronic toothbrush.

\section{Results}

\subsection{Surface Morphology of the Toothpaste}

SEM images of the toothpastes' surfaces were obtained (Fig. 1). The fabricated toothpastes exhibited a rough complexion and comprised with irregularly sized particles. The roughness of the surfaces of the fabricated toothpastes was further highlighted by comparison to commercially available toothpastes. The surface of the samples exhibited irregular particle sizes ranging from a fine powder to flake-like structures. The fillers used were not as fine as those used in the commercial preparations. Also, the presence of HAp further roughened the toothpaste.

The surfaces of the toothpastes' fillers were further analyzed by obtaining their EDS profiles(Fig. 2). In the EDS profile of TP-HP0, low calcium and phosphorus peaks were detected. This may signify the HAp-free toothpaste had minute amounts of $\mathrm{Ca}$ and P. In TP-HP15, the $\mathrm{Ca}$ and $\mathrm{P}$ ratio was increased, consistent with the addition of HAp, which could be a source of calcium and phosphate ions. This indicates that HAp was successfully incorporated to the toothpaste.

The inclusion of HAp to the toothpastes was further studied by obtaining the XRD profile of each fabricated preparation. XRD profiles of HAp, CT-A and CT-B were obtained and were compared to the XRD profiles of TPHP0, TP-HP5, TP-HP10 and TP-HP15. Peaks were present in the TP-HP toothpastes that were comparable to the HAp profile(Fig. 3). The peaks were believed to be

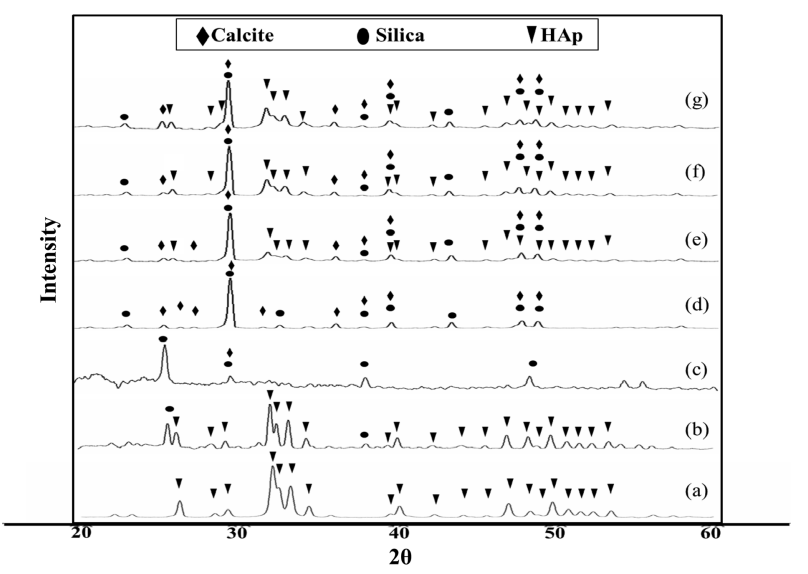

Fig. 3. XRD profile of (a) Hap, (b) CT-A, (c) CT-B, (d) TP-HP0, (e) TP-HP5, (f) TP-HP10 and (g) TP-HP15.

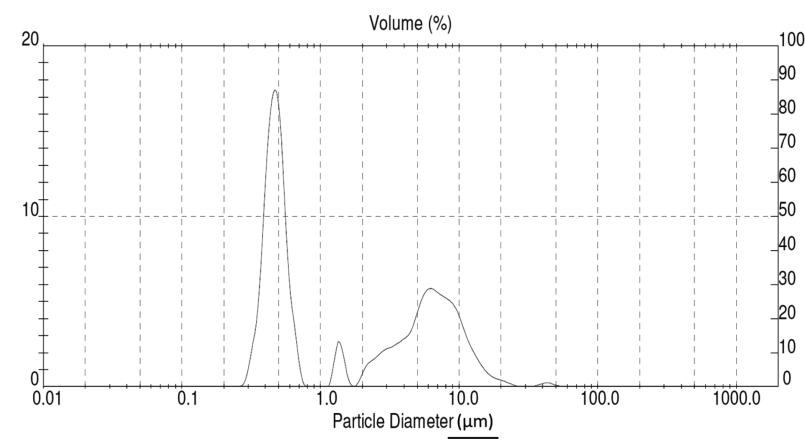

Fig. 4. Particle size analysis of the Hap powder used.

HAp and were also evident in CT-A. A more intensive rate of the peaks was observed in the toothpaste containing higher concentrations of HAp. The most intensive peaks were evident in TP-HP15 among the fabricated tooth-
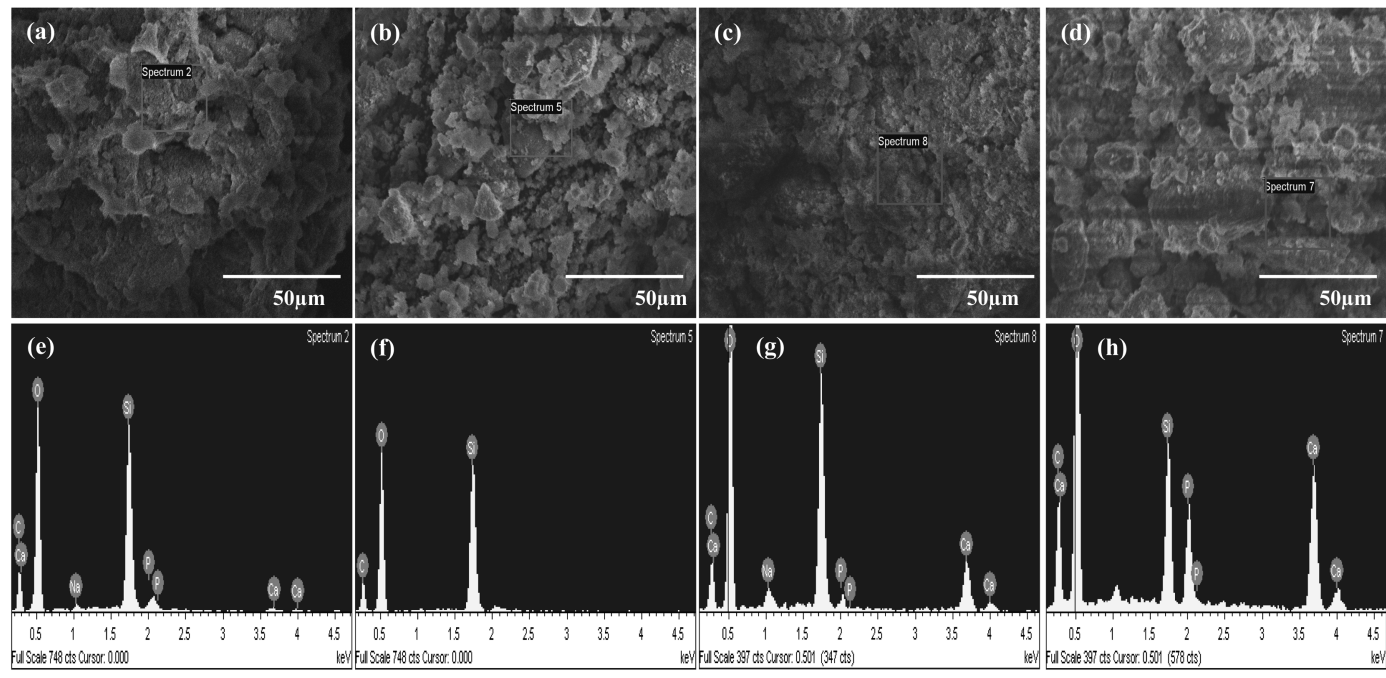

Fig. 2. SEM images of the surfaces of the filler of (a) Commercial toothpaste (CT) A, (b) Commercial toothpaste (CT) B, (c) Toothpaste without Hap, (d) Toothpaste with Hap and its respective EDs profiles (e) Commercial toothpaste (CT) A, (f) Commercial toothpaste (CT) B, (g) Toothpaste without Hap (h) Toothpaste with Hap. 

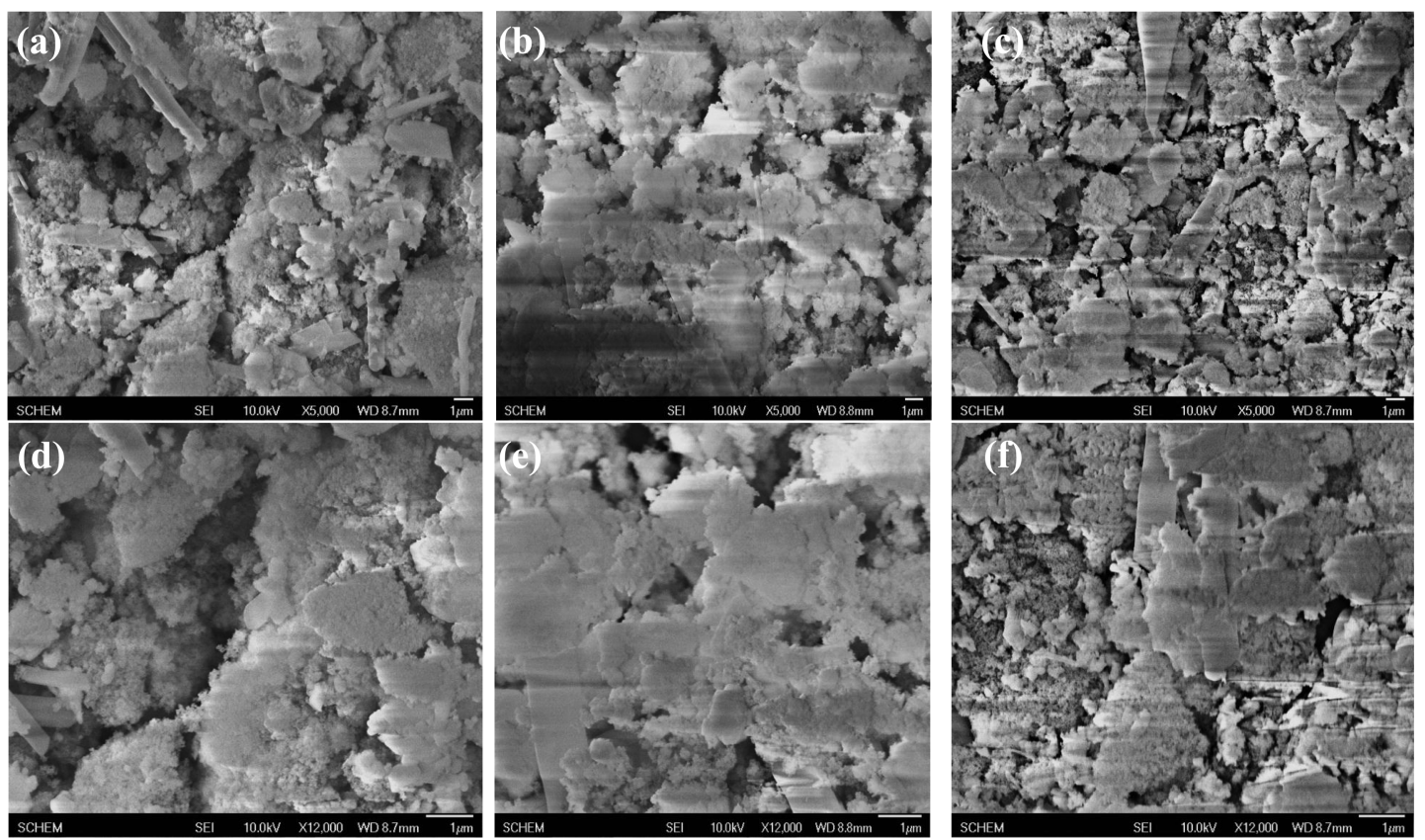

Fig. 5. SEM images of the filler particles of the fabricated toothpastes with Hap (a) TP-HP5, (b) TP-HP10 and (c) TP-HP15 and higher magnification (d), (e), and (f).

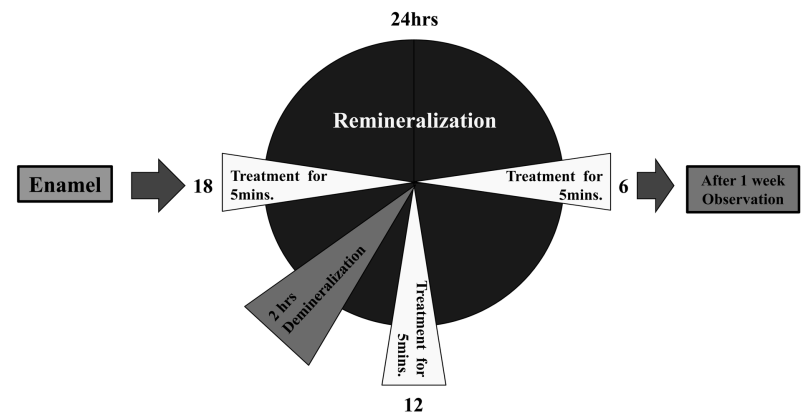

Fig. 6. Schematic diagram of the $\mathrm{pH}$ cycling model used in the treatment of the samples.

pastes. This pattern supported the view that HAp was successfully incorporated in the toothpastes. The other peaks were not analyzed as the experiment sought only to prove the existence of HAp in the toothpastes samples. But some were too predominant and were observed to be either calcite or silicate. These two compounds were suspected to be present in the samples as they were commonly used as abrasives in toothpastes. ${ }^{21)}$

The particle sizes of the HAp powders were fairly irregular, producing non-uniformed roughness for the toothpaste(Fig. 4). In this scenario, the toothpaste can be improved via further refinement of the HAp powder.

The effect of the HAp particle size was further observed in SEM images of filler materials of the toothpaste. The roughness increased and presence of more blocks was observed in the toothpaste as the concentration of HAp increased(Fig. 5). The fillers of the samples were further observed, in which bigger filler particles were observed in the toothpastes incorporated with HAp compared to that of without HAp and to the commercial toothpastes.

\subsection{Human enamel characterization}

SEM images of the teeth were observed before and after treatment. Physical cavities were observed prior to scaling(Fig. 7). Scaling was conducted to ensure that no other impairment was present with the teeth before the infliction of artificial lesions. Surfaces of the human enamel were observed once again after 7 days of treatment (Fig. 8). Crystal-like shapes were present on the surface of the teeth and seemed to be attached. The surface was rough due to the presence of the crystal-like structures.

\subsection{Lesion Depth Measurement}

Artificial lesions were created on human enamel to measure the ability of the toothpaste to fill in cavities and stop tooth decay. Depths of the lesions were measured to obtain an estimation of their areas. Microscopic images of the teeth with the inflicted artificial lesion before treatment are shown in Fig. 9. It was hypothesized that lesion depth would decrease after treatment with the fabricated toothpaste containing HAp. Microscopic images of the artificial lesions after 7 days of treatment revealed a change in the appearance of the lesion area(Fig. 10). The area seemed to be more irregular showing a rougher lining of the cavities compared to that before treatment. The changes in lesion depth of the human enamels are summarized more clearly in Table 1 . The areas of lesion 


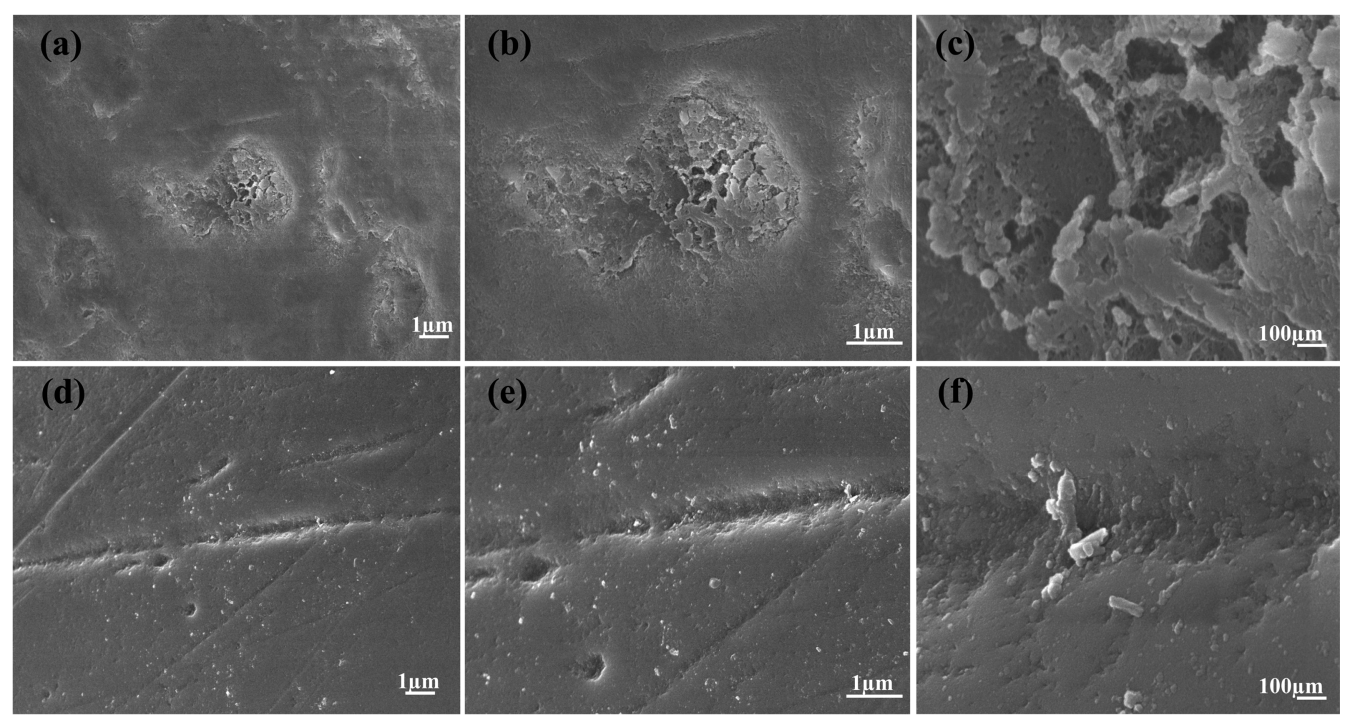

Fig. 7. SEM images of the particles of the teeth surface (a) Before scaling (b) and (c) higher magnification of before scaling and (d) surface of the teeth after scaling (e) and (f) higher magnification.

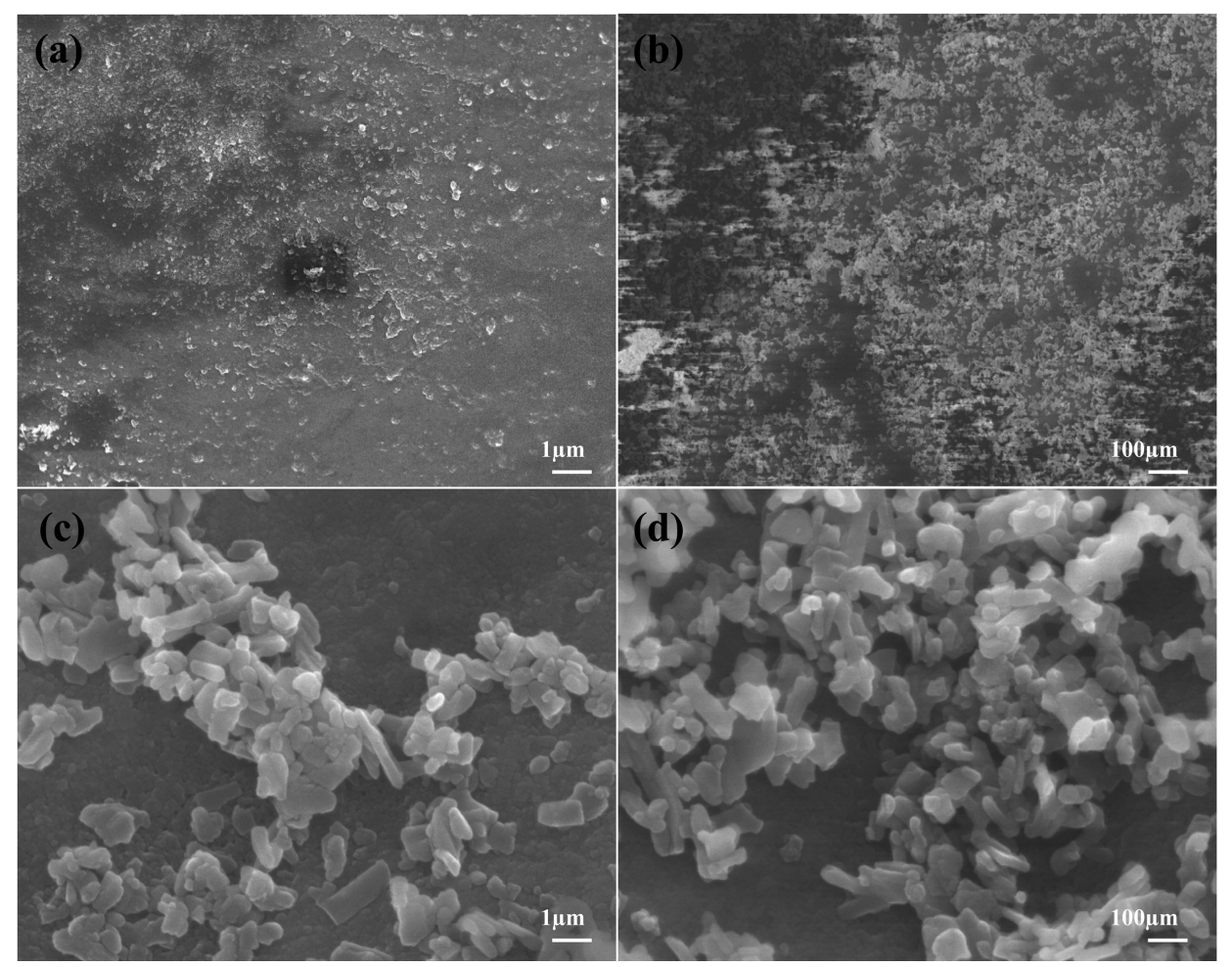

Fig. 8. SEM images of the particles of the teeth surface after treatment with (a) TP-HP0 and (b) TP-HP15. (c) and (d) are the respective higher magnification.

depth were measured before and 7 days after treatment. The area of the lesions was assumed to be of rectangle shape and the areas were computed in accordance with the formula used to measure the area of a rectangle. Area of each lesion was computed as length/height of the lesion $\mathrm{x}$ width of the lesion. Change in lesion depth was computed as follows:
Difference in area $=$ Area of the initial time - Area after 7 days of treatment

$\%$ Change $=($ Difference in area $\div$ Initial area $) \times 100$

TP-HP15 registered the highest change in lesion depth having a $37.15 \%$ difference in the area measurement of the lesion after 7 days of treatment(Table 1). TP-HP0 or 
174 Alexander Sadiasa, Jang Dong-Woo, Subrata Deb Nath, Hyung Seok Seo, Hyn Mo Yang and Byong Taek Lee
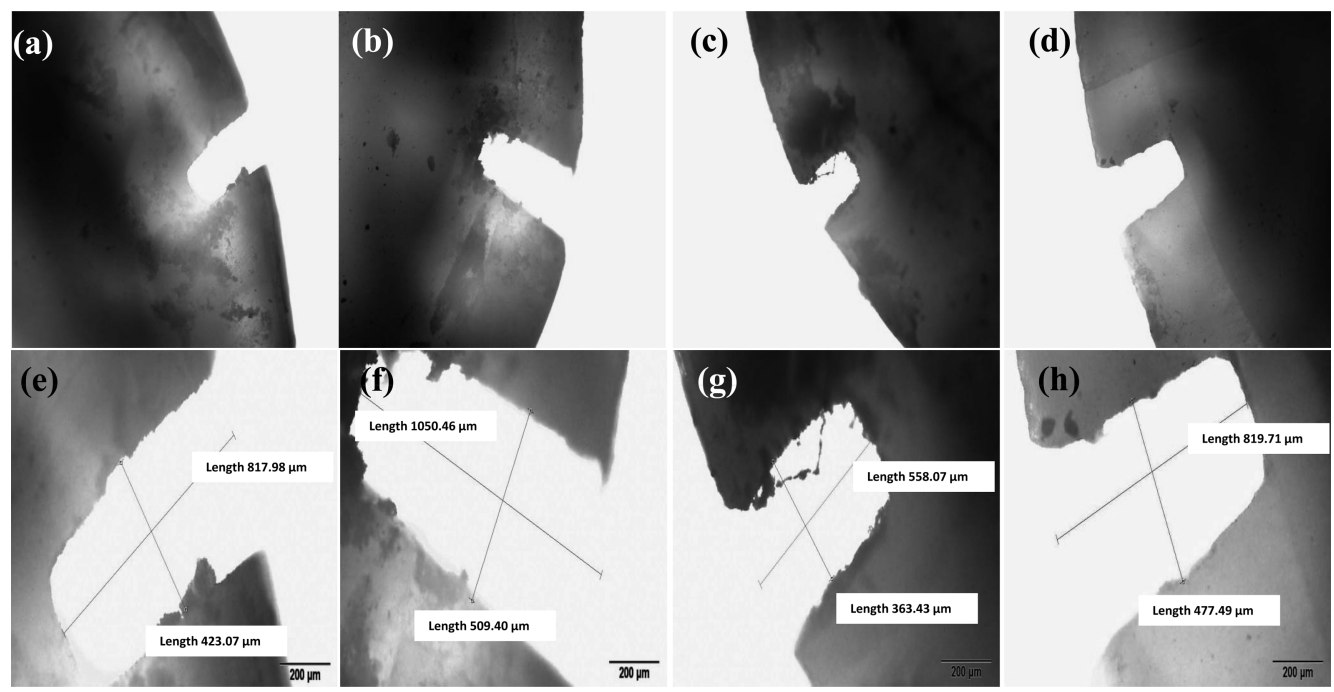

Fig. 9. Microscopic images of the artificial lesions in the bovine enamel used in the treatment with (a) TP-HP0, (b) TP-HP5, (c) TP-HP10, (d) TP-HP15 and higher magnification with scale measurements (e) TP-HP0, (f) TP-HP5, (g) TP-HP10 and (h) TP-HP15.
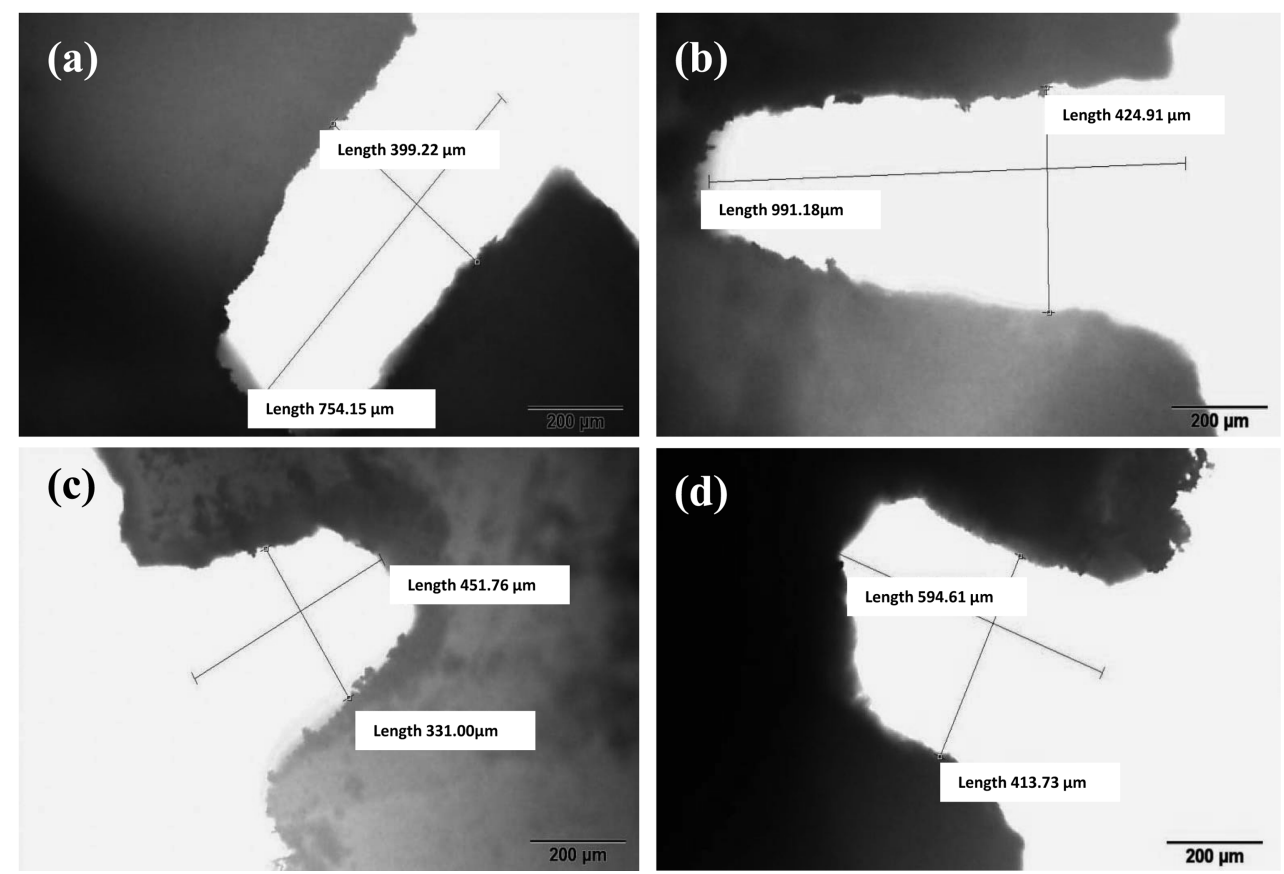

Fig. 10. Microscopic images of the artificial lesions in the bovine enamel used in the treatment with (a) TP-HP0, (b) TP-HP5, (c) TPHP10 and (d) TP-HP15 after 1 week of treatment.

Table 1. Measurement of depth of the artificial lesion.

\begin{tabular}{|c|c|c|c|c|c|c|c|c|}
\hline \multirow{2}{*}{ Sample } & \multicolumn{3}{|c|}{ Initial time (um) } & \multicolumn{3}{|c|}{ After 1 week (um) } & \multirow{2}{*}{$\begin{array}{c}\text { Difference in } \\
\text { Area }\left(\mathrm{um}^{2}\right)\end{array}$} & \multirow{2}{*}{$\%$ change } \\
\hline & Length & Width & Area & Length & Width & Area & & \\
\hline TP-HP0 & 817.98 & 423.07 & 346062.80 & 754.15 & 399.22 & 301071.76 & 44991.04 & 13.00 \\
\hline TP-HP5 & 1050.46 & 509.40 & 535104.32 & 991.18 & 424.91 & 421162.29 & 113942.03 & 21.29 \\
\hline ТР-HP10 & 558.07 & 363.43 & 202819.38 & 451.76 & 331.00 & 149532.56 & 53286.82 & 26.27 \\
\hline TP-HP15 & 819.71 & 477.49 & 391403.33 & 594.61 & 413.73 & 246008.00 & 145395.33 & 37.15 \\
\hline
\end{tabular}

that of without HAp, registered the lowest change in lesion depth with a mark of $13.00 \%$. This signifies that as the
HAp concentration in the fabricated toothpastes increases, the ability of the toothpaste to restore the lesions and 
cavity of the human enamel increases.

\section{Discussion}

Enamel is the part of the tooth covering the entire anatomic crown, which protects the dentin and the pulp. ${ }^{22}$ The enamel is formed when the crown of the tooth is completed as synthesized by ameloblasts, an epithelialderived cell of the enamel organ. Ameloblasts secrete and mineralize the enamel matrix. These ameloblasts are also known as epithelial cells that lose their function. Thus enamel, after formation, has no capacity to further grow or repair its damage and only loss minerals. ${ }^{23,24)}$

This study investigated the effect of the incorporation of HAp to toothpaste in the regeneration of dental caries. HAp is a good biomaterial, especially in the field of bone engineering, because of its biocompatibility and osteoconductivity, which covers a wide range of applications for bone substitution and interface. ${ }^{25}$ As studied, enamel maintains a $\mathrm{Ca}: \mathrm{P}$ ratio of 1.63 compared to the general HAp ratio of 1.67 and bone, 1.71 thereby forming a chemical relationship between the three, making it possible for HAp to be used for dental regeneration. ${ }^{23)}$ In this study, complete incorporation of HAp to the toothpaste was confirmed using XRD and SEM. The fabricated toothpastes had rougher surfaces than the commercially available toothpastes. It can be generalized that the HAp produced from this laboratory were not as fine as the abrasives used in the commercial toothpaste. The goal remains to generate HAp with a very fine particle size in the hope that it will reach the hard-to-reach parts of the teeth, especially the inner part of a dental lesion.

In this study, a pH cycling model(Fig. 6) was used to mimic/copy the daily occurrences in the mouth. Remineralization solution served as the artificial saliva while demineralizing solution simulated the daily acid challenges experienced by the teeth. The health of teeth, which are considered to be a mineralized tissue, is greatly affected by demineralization and remineralization processes. ${ }^{2}$ The possible continuation of dental caries or lesions proliferation depends on these processes. Balance between demineralization and remineralization should be maintained and depend on several factors, such as salivary calcium (Ca) and phosphate $(\mathrm{P})$ concentration, bioavailability of fluoride and $\mathrm{pH}$. Mineral loss can be attributed to the degree of $\mathrm{Ca}$ and $\mathrm{P}$ saturation and the $\mathrm{pH}$ of the solutions with respect to apatite materials. Enamel is composed of many apatite crystals that are together to form prisms to ensure high mechanical integrity and protection from the everyday hazards. Remineralization may occur when the $\mathrm{pH}$ rises, thus promoting the formation of hydroxyapatite crystals in the tooth surface through the interaction of salivary $\mathrm{Ca}$ and $\mathrm{P}$ with fluoride. ${ }^{5,18,26)}$ This will explain the crystal or block-like appearances in the surface of the enamel seen in Fig. 8.

Presently, it was observed that restoration of dental lesions was improved by the addition of HAp to the toothpaste. At normal $\mathrm{pH}$, the supersaturation of saliva with $\mathrm{Ca}$ and $\mathrm{P}$ is enough to counter the daily acid situations brought about by the normal individual's diet. ${ }^{27)}$ However, when the mouth is infected with bacteria such as Streptococcus mutans and Lactobacilli, weak organic acids are produced from glycolysis when these bacteria ingest sugars. These acids lower the oral $\mathrm{pH}$, which leaches the $\mathrm{Ca}$ and $\mathrm{P}$ from the enamel, compromising the mechanical structure of the tooth and leading to the formation of dental lesions. ${ }^{28)}$ This attack on the apatite layer of the enamel seems to be addressed by the addition of HAp to the toothpaste as it will be able to supply more $\mathrm{Ca}$ and $\mathrm{P}$ ions during the remineralization process, thus making the restoration of the dental lesion faster. During remineralization, the mineral-deprived layers of enamel can serve as nucleation sites for new mineral deposition, wherein $\mathrm{Ca}^{2+}$ and $\mathrm{PO}_{4}{ }^{3-}$ ions in saliva settles as new apatite layers. ${ }^{29)}$

The addition of HAp is supposed to decrease the use of fluoride in the toothpastes, which may be beneficial given that excessive use of fluoride may be detrimental. Low levels of fluoride present in saliva and plaque can inhibit demineralization and enhance remineralization, preventing the formation of caries and perhaps even reversing it. ${ }^{30)}$ Upon the addition of HAp, there is a possibility that the $\mathrm{OH}^{-}$ion in the HAp will be completely replaced by a fluoride $\left(\mathrm{F}^{-}\right)$, which will result to the formation of fluoroapatite $\left(\mathrm{Ca}_{10}\left(\mathrm{PO}_{4}\right) 6 \mathrm{~F}_{2}\right)$. Fluoroapatite is very resistant to dissolution by acid making it more stable during the demineralization/remineralization cycle. After remineralization, with the reaction between fluoride and HAp, the enamel will be composed of both HAp and fluoroapatite, making it less soluble during acid attacks than its original state. ${ }^{31)}$ In this case, during demineralization, the addition of HAp will increase the rate of HAp and fluoride reaction forming more fluoroapatite layers. In this case, dissolution rate of the apatite layer will decrease while another layer will be added during remineralization. This explains the decrease in the depth of the artificial lesion evident in Fig. 10 and Table 1, in which as the concentration of HAp incorporated in the toothpaste increased, the greater wasthe change in the depth of the artificial lesions after the treatment.

\section{Conclusion}

HAp was successfully incorporated in the toothpastes and was confirmed using SEM and XRD. The toothpastes produced with varying concentrations of HAp were characterized. The fabricated toothpaste with HAp had a 
rougher appearance compared to the commercially available toothpastes and the roughness further increased as the concentration of HAp increases. An improved Ca:P ratio, which is essential in mineralized tissues, was also observed in the toothpaste as the HAp concentration increased. After treatment with the toothpaste and undergoing $\mathrm{pH}$ cycling, the surface of the teeth samples were covered with crystal-like structures and the depth of the artificial lesions decreased. A more pronounced change was observed in the teeth treated with the toothpaste containing higher concentration of HAp, indicating the capability of HAp in teeth restoration.

\section{Acknowledgement}

"This study was supported by a grant from the Korea Health Technology R \& D Project, Ministry of Health and Welfare, Republic of Korea (A111084)."

\section{References}

1. W. Xia, J. Lausmaa, P. Thomsen and H. Engqvist, J. Biomed. Mater. Res. B., 100B(1), 75 (2012).

2. C. Poggio, M. Lombardini, M. Colombo and S. Bianchi, J. Dent., 38(11), 868 (2010).

3. I. Diamanti, H. Koletsi-Kounari, E. Mamai-Homata and G. Vougiouklakis, J. Dent., 39(9), 619 (2011).

4. N. Hiraishi, C. K. Y. Yiu, N. M. King and F. R. Tay, J. Dent., 37(6), 440 (2009).

5. L. Li, H. Pan, J. Tao, X. Xu, C. Mao, X. Gu and R. Tang, J. Mater. Chem., 18(34), 4079 (2008).

6. T. Aoba, Oral Dis., 10(5), 249 (2004).

7. M. Niwa, T. Sato, W. Li, H. Aoki, H. Aoki and T. Daisaku, J. Mater. Sci. Mater. Med., 12(3), 277 (2001).

8. N. Roveri, E. Battistella, C. L. Bianchi, I. Foltran, E. Foresti, M. Iafisco, M. Lelli, A. Naldoni, B. Palazzo and L. Rimondini, J. Nanomater., 2009, (2009).

9. S. Huang, S. Gao, L. Cheng and H. Yu, J. Dent., 38(10), 811 (2010).

10. D. T. Zero, R. F. Raubertas, J. Fu, A. M. Pedersen, A. L.
Hayes, and J. D. B. Featherstone, J. Dent. Res., 71(11), 1768 (1992).

11. J. M. ten Cate and P. P. E. Duijsters, Caries Res., 16(3), 201 (1982).

12. A. K. Burwell, L. J. Litkowski and D. C. Greenspan, Adv. Dent. Res., 21(1), 35 (2009).

13. A. Balamurugan, A. H. S. Rebelo, A. F. Lemos, J. H. G. Rocha, J. M. G. Ventura and J. M. F. Ferreira, Dent. Mater., 24(10), 1374 (2008).

14. S. M. Levy, J. Can. Dent. Assoc., 69(5), 286 (2003).

15. S. Zimmer, K. Jahn and C. Barthel, Oral Health Prev. Dent., 1(1), 45 (2003).

16. J. D. B. Featherstone, Adv. Dent. Res., 21(1), 4 (2009).

17. A. Itthagarun, N. M. King and Y. M. Cheung, Hong Kong Dent., 7(2), 61 (2010).

18. P. Tschoppe, D. L. Zandim, P. Martus and A. M. Kielbassa, J. Dent., 39(6), 430 (2011).

19. Y. S. Kim, H. K. Kwon and B. I. Kim, J. Dent., 39(9), 636 (2011).

20. C. Domingo, R. W. Arcís, E. Osorio, R. Osorio, M. A. Fanovich, R. Rodríguez-Clemente and M. Toledano, Dent. Mater., 19(6), 478 (2003).

21. F. N. Hattab, J. Dent., 17(2), 47 (1989).

22. R. Z. Legeros, Adv. Dent. Res., 2(1), 164 (1988).

23. P. K. DenBesten, D. Machule, Y. Zhang, Q. Yan and W. Li, Arch. Oral Biol., 50(8), 689 (2005).

24. J. P. Simmer and A. G. Fincham, Crit. Rev. Oral Biol. M., 6(2), 84 (1995).

25. N. Roveri, E. Battistella, C. L. Bianchi, I. Foltran, E. Foresti, M. Iafisco, M. Lelli, A. Naldoni, B. Palazzo and L. Rimondini, J. Nanomater., 2009, (2009).

26. W. Arnold, A. Haase, J. Hacklaender, Z. Gintner, J. Banoczy and P. Gaengler, BMC Oral Health, 7(1), 14 (2007).

27. M. J. Larsen and E. I. F. Pearce, Arch. Oral Biol., 48(4), 317 (2003).

28. A. E. Winston and S. N. Bhaskar, J. Am. Dent. Assoc., 129(11), 1579 (1998).

29. J. D. Featherstone, J. Am. Dent. Assoc., 131(7), 887 (2000).

30. L. J. Walsh, J. Dent. Assoc. S. Afr., 11(6), 6 (2009).

31. J. D. B. Featherstone, Community Dent. Oral Epidemiol., 27(1), 31 (1999). 